\title{
RENACER. Retrovanguardismo en El Ejército de la llíada de Leopoldo Lugones. 1908-1915
}

\author{
REBORN. Retro-avant-garde in The Army of the Iliad by Leopoldo Lugones. 1908-1915
}

\author{
Javier Tobares \\ Facultad de Filosofía y Humanidades/Universidad Nacional de Córdoba (FFyH, UNC), Argentina \\ javiertobares78@gmail.com
}

\section{Resumen:}

El presente artículo constituye el avance parcial de un trabajo más amplio que se encuentra en desarrollo en el contexto de nuestra tesis doctoral Encrucijada. El concepto de pueblo en la obra de Leopoldo Lugones. 1910-1932 (FFyH, UNC, 2017). La conmemoración del Centenario de la Revolución de Mayo es el momento en el que Lugones traza, desde su perspectiva, la articulación de un discurso que pretendía redefinir los parámetros de organización social y política. Las cuatro obras en que plasma su proyecto funcionan como un recurso retrovanguardista en el que el tiempo se condensa en un pasado que se remite -no sin tensiones- a la Grecia clásica y proyecta a la Argentina al futuro, desde un presente que se percibe como una situación de vacío temporal, un momento (re)fundador de una utopía sociopolítica. Así, la tetralogía del Centenario constituye en el punto de referencia desde donde Lugones comprime el tiempo de su relato, recupera el pasado y lo proyecta al futuro en El Ejército de la Iliada (1915).

Palabras ClaVe: Lugones, Pueblo, Fuerzas Armadas, Modernismo.

\section{Abstract:}

This article constitutes the partial progress of a larger work that is under development in the context of our doctoral thesis Crossroads. The concept of people in the work of Leopoldo Lugones. 1910-1932 (FFyH, UNC, 2017). The commemoration of the Centennial of the May Revolution is the moment in which Lugones traces, from his perspective, the articulation of a discourse that sought to redefine the parameters of social and political organization. The four works in which he draws his project work as a retro-avant-garde resource in which time condenses into a past that refers - not without tensions- to classical Greece and projects Argentina to the future, from a present that is perceived as a situation of temporary emptiness, a (re) founding moment of a sociopolitical utopia. Thus, the tetralogy of the Centenary constitutes the point of reference from which Lugones compresses the time of his story, recovers the past and projects it into the future in El Ejército de la Iliada (1915).

KEYwoRDs: Lugones, People, Armed Forces, Modernism.

"La originalidad es una ilusión de los revolucionarios ficticios. No hay nada nuevo, excepto lo que se ha olvidado." Laibach, Declaraciones ${ }^{1}$.

\section{INTRODUCCIÓN}

La conferencia en el Círculo Militar en 1909 es, en primer lugar, un punto de inflexión en los planteos de Leopoldo Lugones (1874-1938), puesto que en su producción discursiva es posible advertir el carácter retrovanguardista ${ }^{2}$ de su reflexión sobre la propuesta de un modelo que ancla en el pasado el diseño a futuro del orden político en Argentina, y, en segundo lugar, el momento en el que sus ideas cobran conciencia de

Recepción: 25 de abril de 2018 | Aprobación: 24 de agosto de 2018 | Publicación: 28 de mayo de 2019 
sí mismas y se plasman en el proyecto político que Lugones expone en la conferencia y publica un tiempo después. Es un pasaje sin solución de continuidad desde una crítica inicialmente anclada en una dimensión ideológica socialista (implícitamente anarquista), pasando por la defensa conservadora y, finalmente, a una posición corporativo-totalitaria del orden social, Lugones es un exponente particular de las transformaciones del pensamiento de las elites intelectuales del período de entreguerras ${ }^{3}$. El eje que atraviesa de principio a fin su producción es aquel que sostenía que la razón era la base del orden y éste se traduciría en (un tipo de) organización social surgida necesariamente de la revolución. En el pensamiento de Lugones, la razón, como elemento de civilización, hacía necesaria la autoridad de una elite sobre las masas, entendidas como entidades irreflexivas arrastradas por pasiones.

¿Por qué Lugones recupera la epopeya de Homero y hace de las FFAA su principal interlocutor y destinatario? ¿Qué procesos, valores y jerarquías están presentes en el discurso de Lugones? ¿Cómo articula el concepto de pueblo en su proyecto político? ${ }^{4}$ ¿Por qué un texto que se escribe en 1908 y se hace público al año siguiente, es publicado en 1915? ¿Cómo se articula con la tetralogía del Centenario del autor?

En la idea del retorno palingenésico, ¿no está contenido el socialismo primitivo de Lugones -su rechazo a la burguesía y su manifestación partidaria, una sociedad sin clases, el pueblo formado en la guerra, devenida en revolución, el rol central del Estado como instrumento de organización social- ahora redefinido por el vitalismo nietzscheano?

El presente trabajo se enmarca dentro de una historia conceptual de lo político, campo de trabajo que se propone articular la historia de los conceptos políticos con la historia de los discursos políticos ${ }^{5}$. Entendemos que los conceptos no son el significado de las palabras, sino que "cambian su significado interactuando con el tiempo histórico, y son por ello no sólo indicadores sino también factores de la realidad histórica" (Sánchez Prieto, 2012, p. 489). Este enfoque permite abordar la realidad discursiva, las prácticas con significado y las redes conceptuales que los contienen. Al mismo tiempo, hace posible "dar prelación a la lucha política como variable explicativa del cambio en los significados de los conceptos a través del tiempo" (Cruz Rodríguez, 2011, p. 59). Así, desde esta perspectiva, tenderemos a enfocarnos en "las condiciones de ensayo o 'puesta a prueba' de lo político, analizando sus límites, antinomias, puntos de equilibrio, las decepciones y desarraigos que suscita". Tomaremos como objetos fundamentales las fracturas, tensiones, límites y negociaciones alrededor del concepto de pueblo (Cruz Rodríguez, 2011, p. 61) a partir de una matriz discursiva que los remite al mismo conjunto de representaciones e ideas que "constituyen una materia estructurante de la experiencia social" que constituyen en sí mismas "reales y poderosas 'infraestructuras' de la vida de las sociedades" (Rosanvallon, 2003, p. 46).

Preguntarse por el vínculo entre la obra de Lugones en relación al nacionalismo, el autoritarismo o "la derecha" es hacer las preguntas equivocadas y obtener las respuestas incorrectas. En el contexto de crisis de la modernidad misma, expuesta en la impugnación de los principios políticos del liberalismo y de la ubicua amenaza del proletariado, Lugones se sitúa en "un nuevo comienzo" que borra los criterios políticos de la modernidad y los trasciende desde una acción liminar refundadora, en un ámbito en el que, al mismo tiempo que "las ideologías híbridas crecían a sus anchas, la diferencia entre izquierdas y derechas era bastante fluida" (Griffin, 2010, p. 194). En general, estas ideologías hibridas servían para:

(...) legitimar distintos proyectos sociopolíticos, tanto de izquierdas como de derechas, con tal de que su fin último fuera una inaugurar una nueva visión de la realidad y una nueva era histórica, y desdeñaran el mecanismo de equilibrio de poderes del racionalismo (Griffin, 2010, p. 195) ${ }^{6}$.

Puesto que lo que define a la nación es el pueblo, en tanto "comunidad imaginada" (Anderson, 1993, p. 23), es allí donde hay que buscar las respuestas. El supuesto "fracaso" 7 del proyecto político de Lugones, atribuido entre otras razones a "su ausencia de todo sentido práctico, su incapacidad para analizar la realidad como algo externo a su voluntad o su exacerbado individualismo" (Devoto, 2008, p. 26) no fue tal, ya que 
la obra de Lugones contribuyó a definir la matriz discursiva común de los gobiernos de facto surgidos de los golpes de Estado en Argentina durante el siglo XX.

Dicho fracaso, en todo caso, puede ser circunscripto a su contexto, y obedeció en todo caso a dos factores coyunturales que desembocaron en la clausura de dicho proyecto. Por un lado, desde "la derecha", el rechazo del establishment conservador que logra acceder al gobierno en 1932 y parece advertir el potencial revolucionario de un proyecto que no responde a sus intereses políticos. Por el otro, desde "la izquierda", el rechazo y la condena al ostracismo de un socialista cuyas propuestas políticas y sociales cristalizan en un proyecto que se le opone frontalmente, que adopta los métodos revolucionarios pero asignándoles un nuevo sentido ( $c f r$. Nolte, 2001, p. 159). Desde este lado del campo político esto no sólo no será olvidado, sino que, por el contrario, será desfigurado y marcado como un espasmo dictatorial de "la derecha". Desde su expulsión del Partido Socialista en 1903, hasta reescrituras historiográficas que sitúan a Lugones como un "intelectual autoritario" (Echeverría, 2009, p. 22) en el elenco de "la derecha jerárquica" (Echeverría, 2009, p. 23) que imagina un orden "militar y represivo" (López, 2004, p. 132), los estudios sobre Lugones se sitúan en un lugar común de escritura de la historia que atiende a la forma del problema, el nacionalismo, y no a su fondo: el sujeto constituyente del poder. Por ello es posible seguir llamando socialista a Lugones en el período considerado, en particular porque "no le interesaba la actividad pública en sí misma -la política como conflicto y como operación- sino como gestión estatal de la sociedad" (López, 2004, p. 106).

Entendemos por matriz discursiva al conjunto dinámico de recursos ontológicos articulado en narraciones o formaciones discursivas que desde la enunciación (re)organizan (por su carácter performativo) el tejido social y que son capaces de dar sentido a las maneras de percibir el orden social. Los proyectos hegemónicos proponen y exigen a los actores sociales adaptarse a una matriz discursiva, a través de la apropiación y legitimación de nociones específicas ${ }^{8}$.

Una matriz discursiva tiende a imponer un sentido compartido de los contrastes y contradicciones, al tiempo que permite cierto entendimiento del orden social. Es un recurso que establece las reglas para reconocer las características de un orden ético y moral que permite la restauración performativa de la cohesión social, y mediante el cual se establecen al mismo tiempo las pautas generales de funcionamiento del orden social. Como expresión de sentido una matriz discursiva se halla necesariamente inserta en condiciones sociales de producción históricamente situadas. En el caso de Lugones entre 1908 y 1915, la teoría de la palingenesia ${ }^{9}$ aparece como la encrucijada entre un mundo en fase de construcción y el mundo real existente (López, 2004, p. 156). Ello nos permite entender el paso de la "izquierda" a la "derecha" en el pensamiento de nuestro autor si consideramos que: "Un marxismo que pierde su alma (es decir, la mirada hacia un futuro caracterizado por una sociedad sin clases), pero que retiene en sus brazos la fuerza y en sus manos la espada, tiende necesariamente al fascismo" (López, 2004, p. 158). Esta transición se da en Lugones en torno al Centenario.

En la idea de acción, ésta se encuentra presente en el medio revolucionario como factor de cambio y retorno. El proyecto político de Lugones no fue la guerra ${ }^{10}$, fue la revolución entendiendo que en esta se hallaba contenido el cambio social frente a una situación de crisis. Ello permite articular el contenido de la conferencia de 1909, con el espíritu y la recuperación performativa del Centenario de la Revolución de Mayo en la tetralogía en la que rinde su "homenaje". En el corpus analizado, el destinatario construido en el discurso lugoniano serán las FFAA, como agentes del cambio social y ejecutores de la violencia. En este sentido, más que recuperar la épica de la guerra, la propuesta de Lugones plantea llevar adelante una revolución, en tanto "cambio de la estructura fundamental de la organización política de la nación". Lo específico de una revolución resultaba ser entonces:

(...)su carácter popular y por eso, cuando triunfa, abre una nueva legalidad, contrariamente a lo que sucede con el golpe de Estado, que casi siempre, por no decir siempre, tiene carácter militar y por eso, por no significar una revolución popular, es, aun triunfante, irremisiblemente ilegal (Ossorio y Cabanellas, 2010, p. 858) ${ }^{11}$. 
Por lo tanto, es necesario para Lugones definir al pueblo como condición previa para la instauración de un nuevo orden. El pueblo aparece entonces como base revolucionaria y sujeto de la nueva legalidad democrática.

Nuestra interpretación histórica sostiene la siguiente tesis: Lugones advierte el doble cierre a la democracia. En primer lugar, dicho cierre era advertido por nuestro autor en la incapacidad de los conservadores reformistas y la salida de 1912. En segundo lugar, el avance imparable del radicalismo parecía hacer necesario repensar a la democracia, a su sujeto constituyente y, en general, a las jerarquías sociales. Y la alternativa que en este contexto entiende, desde su propio espacio de experiencia, como la más adecuada para superar esa situación se encarna (una vez más, desde una perspectiva palingenésica) en lo que él piensa como una nueva aristocracia: las FFAA.

\section{El Demiurgo}

La conmemoración del Centenario de la Revolución de Mayo fue el marco en el que nuestro autor asimiló el clima de exaltación imperante, momento en el que también asumía la presidencia de la nación Roque Sáenz Peña, que consolidaría la facción reformista de los grupos conservadores que habían gobernado el país desde 1880, y se propondría acabar con el fraude electoral impulsando la reforma electoral en 1912, que abriría las puertas de par en par a la participación electoral del pueblo definido por la misma ley (Tobares, 2017a).

Como aporte a la conmemoración, Lugones publica una tetralogía en la que presenta:

El intento más serio, a partir de Las Bases, de estructurar un nuevo programa nacional. Pero, a diferencia de la obra de Alberdi, Lugones propicia el aniquilamiento del materialismo imperante, verdadera epopeya del filisteo burgués, cuya pedestre visión del mundo habíase enseñoreado en ideología oficial. Lo que pregona, sin segundas intenciones, es una espiritualidad desinteresadamente sincera que no encubre (...) un materialismo tan feroz como el que se pretende suplantar (Conil Paz, 1985, p. 122).

Lugones llevó adelante en la conferencia de 1909, luego publicada como El ejército de la Ilíada en 1915, una reconstrucción performativa ${ }^{12}$, en la cual asignó al Ejército el protagonismo en el retorno de la tradición como agente promotor de la civilización. Esta recuperación arbitraria funcionó como argumento político que le permitió construir al destinatario de su proyecto: el Ejército, al que situaba a un mismo tiempo como protagonista de la epopeya homérica y promotor del cambio social. Esta operación es la que permite advertir la dimensión retrovanguardista de su discurso. En éste, el héroe modelo es Héctor, agente civilizador que acepta voluntariamente la muerte como acto de afirmación de la identidad nacional ${ }^{13}$. El lugar del pueblo es presentado como consecuencia de la acción de los jefes, surgido a partir de la asociación deliberativa originada en la guerra, y, por lo tanto, portador implícito de las jerarquías del campo de batalla. Ello (re)define el concepto mismo de democracia incluyendo negativamente ${ }^{14}$ al sujeto portador de soberanía.

En este contexto, Lugones se presenta a sí mismo como demiurgo, enunciador autorizado de ese retorno y proyección, de ese renacer de la cultura clásica en Argentina. Éste es el carácter retrovanguardista en el propio Lugones. El destinatario es construido como el ejecutor de esos valores, y encuentra al sujeto de la performance en las FFAA.

La conferencia de 1909 abre en la obra de Lugones un diálogo con las FFAA en el cual el poeta se presentará a sí mismo como intérprete de verdades y juicios olvidados que se recuperan frente al inminente colapso de la cultura occidental. La amenaza latente de un potencial conflicto hace del interlocutor de Lugones el destinatario por excelencia para que sus palabras se materialicen como acción. Entiende además que las jerarquías implícitas del cuerpo militar pueden ser trasladadas al orden social, al tiempo que "mantiene un posicionamiento crítico ante el sistema político, y sobre todo ante la tendencia niveladora de la modernidad, que tiene una clara -y para muchos 'preocupante'- expresión política en el poder acumulado por el Partido Radical” (Bustelo, 2012, p. 92). A ello se suma la concreción de la igualdad electoral en 1912. Ésta es considerada como "la instauración de la mediocridad" (Bustelo, 2012, p. 93), que trastoca las jerarquías 
políticas y sociales en beneficio de los partidos liberales cuyos beneficiarios, los políticos, impulsan para beneficiarse con el "simulacro de la representación" y que, más allá de promover la participación del ciudadano, tiene como fin último "la explotación del pueblo por medio de la comedia electoral" (Bustelo, 2012, p. 95), que restringe su libertad y la de los intelectuales a quienes el poeta cordobés señala como "los verdaderos orientadores de la civilización” (Bustelo, 2012, p. 96), y proyecta en su lugar la verdadera acción popular, más allá del voto. En este sentido, los que se hallan fuera del sistema electoral son los referentes últimos de la acción popular:

Éstos son en el terreno militante, los sindicatos, el otro ejército permanente e internacional; y en el filosófico los intelectuales (...) el pueblo sigue otro camino más interesante que el parlamentario; el del gobierno directo por medio del sindicato, de la huelga, del boicot, apoyado por la fuerza efectiva (Bustelo, 2012, p. 95).

El contexto internacional, enmarcado en la Gran Guerra, que en el plano local se combina con la llegada de los radicales a la presidencia en 1916, la Revolución Rusa de 1917 y el movimiento Reformista de 1918, desplaza definitivamente el eje de la reflexión de Lugones desde la nación hacia "las nuevas tendencias estéticas y el porvenir de la civilización como las cuestiones más significativas” (Bustelo, 2012, p. 99). El autor entiende que sólo la definición y adopción práctica de los valores de la civilización occidental clásica permitirá el surgimiento de individuos libres.

Frente a la crisis de la cultura occidental y de la Argentina en particular, la trilogía estética sostenida por Lugones -bien, verdad y belleza- sirve como referencia moral y en ella el poeta asigna el carácter permanente sólo a la última, a la que, al mismo tiempo, dota del sentido de proporcionalidad, y la constituye en el fundamento que permite condensar, contener y encauzar la crisis de la modernidad, a través de una revolución. Pero todo ello en torno al supuesto de que: "El fundamento esencial del arte es el orden, es decir la conformidad perfecta de los elementos que lo constituyen. Cada obra de arte es, desde este punto de vista, una presencia ordenada" (Sallenave, 1984, p. 100).

En este sentido, en la coyuntura de 1910, Lugones entiende que la cultura argentina, heredera de los valores clásicos, está desvirtuada y esto es lo que afirma su espacio de experiencia, al tiempo que tiende a desviarse de un orden social justo:

(...) el régimen político democrático y oligárquico es entendido como una desviación de los valores esenciales de la naturaleza del alma humana. Estos valores se expresan a partir de la fórmula binaria superiores-inferiores, estableciendo un sistema de jerarquías que atraviesa transversalmente -cuando no cuestiona- las posiciones sociales y políticas de la sociedad presente, sin dejar por ello de ser una antropología del poder que excluye a las "masas incultas", sean inmigrantes, sean nacionales (Ferrás, 2008, p. 204).

La tetralogía del Centenario, se instituye como la (re)fundación performativa del mito y "sistematización de lo estético" (Sallenave, 1984, p. 99), que vincula directamente la cultura argentina con la tradición griega. Es en la teratología del Centenario donde la perspectiva retrovanguardista se hace explícita, ya que en estas obras se condensan el espacio de experiencia, la recuperación de la esencia cultural argentina en el mito helénico, y el horizonte de expectativa de su proyecto, el uso del mito para proyectar a la Argentina en el nuevo contexto internacional.

A comienzos del siglo pasado, en un contexto de cambio político en el que el roquismo claudicaba frente al reformismo y la renovación electoral buscaba brindar legitimidad al gobierno, Lugones redefinió la democracia a partir de la recuperación de la experiencia idealizada de la democracia griega y del contraste frente a lo que definió como su propio espacio de experiencia atravesado por la inseguridad de un momento de crisis como el de la Argentina del Centenario, momento mítico y (re)fundante, en el que el poeta apela a la metáfora de la fragua y la forja en la figura de Hefestos para marcar claramente los objetivos de la democracia y los elementos constitutivos del pueblo ${ }^{15}$. Lugones pensaba que el arte heleno era la manifestación más acabada de la vida política clásica, dado que lo entendía como una síntesis estética, filosófica y ética. Era: 
El griego carecía de inquietud (...) Carecía, pues, de la inquietud, la terrible enfermedad moderna que nos conduce a dejar todo inconcluso en la tristeza de un esfuerzo sin objeto. Hoy no sabemos para qué vivimos, desintegrada en la anarquía toda solidaridad humana y hasta patriótica. Aquella gran dicha antigua de sentirse inmortal en la perpetuidad del esfuerzo continuado, ya no existe ${ }^{16}$.

Como hemos señalado, la tetralogía de Lugones recupera el pasado y proyecta al futuro la coyuntura de 1910. El hecho de que dedique cuatro libros a su "homenaje a la patria" otorga cohesión al corpus aquí seleccionado, al tiempo que nos permite exponer el recorrido retrovanguardista de los mismos y entenderlos como punto de inflexión de su pensamiento.

La conmemoración del Centenario de la Revolución de Mayo es el momento en el que Lugones traza, desde su perspectiva, la articulación de un discurso que pretendía redefinir los parámetros de organización social y política. Las cuatro obras en que plasma su proyecto funcionan como un recurso retrovanguardista en el que el tiempo se condensa en un pasado que se remite - no sin tensiones - a la Grecia clásica, y proyecta a la Argentina al futuro, desde un presente que se percibe como una situación de vacío temporal, un momento (re)fundador de una utopía sociopolítica.

Así, Odas Seculares (1910), Prometeo (Un proscripto del sol) (1910), Piedras Liminares (1910) -ambos forman parte de Las Limaduras de Hephestos- y Didáctica (1910) se constituyen en el punto de referencia desde el que Lugones comprime el tiempo de su relato, recupera el pasado y lo proyecta al futuro en El ejército de la Ilíada (1915)

Lugones concebía a los poetas como expertos en el uso del lenguaje, y al poema como fundamento último de la cultura; así, "el poema épico refleja un modo superior de vida: el de la vida heroica" (Sallenave, 1984, p. 102), y es por ello que Lugones desde un poema articula el pasado con el presente.

\section{El FUego y LA FrAguA: El EjÉRCITO DE LA ILÍADA}

Antes de que llegase la "hora de la espada", ésta debía ser forjada. Lugones -como Hephestos- llevará adelante esta tarea. Escrito en 1908 y hecho público en la conferencia en el Círculo Militar al año siguiente, El Ejército de la Ilíada se publicaría en 1915 y constituiría el punto cúlmine de la toma de conciencia de un discurso que se ha instituido como referente estético, y, por tanto, político y social. Es desde esta perspectiva que, siguiendo a Pierre Rosanvallon, abordamos desde lo político el discurso lugoniano, el cual apela al pueblo como sujeto instituyente y a la democracia como régimen a instituir. Por ello, Lugones entiende que es preciso:

(...) partir de la complejidad de lo real y de su dimensión aporética conduce a interesarse por la "cosa misma" de lo político. Así, en primer lugar, hay que considerar el carácter problemático del régimen político moderno para comprender su funcionamiento y no para buscar resolver su enigma imponiéndole una normatividad (Rosanvallon, 2003, p. 42).

Ello hace necesario repensar el significado de la democracia, y de las tensiones implícitas en su definición y práctica, ya que en éstas se hallan "reales y poderosas 'infraestructuras' de la vida de las sociedades" (Rosanvallon, 2003, p. 46) en un contexto en el que los cambios internacionales y locales redefinían las relaciones entre gobierno y sociedad civil ${ }^{17}$. Esto se hace más evidente, en particular, si consideramos que uno de los aspectos característicos de la modernidad es que fue concebida, como sostiene Reinhart Koselleck, "como un tiempo nuevo desde que las expectativas se han ido alejando cada vez más de las experiencias hechas" (Koselleck, 1993, p. 343). Entonces, allí donde las tensiones fueron extremas, "allí, donde en el plazo de una generación se rompió el espacio de experiencia, todas las expectativas se convirtieron en inseguras y hubo que provocar otras nuevas" (Koselleck, 1993, p.344) ${ }^{18}$.

En este sentido, el manejo de un tiempo heterogéneo y maleable se halla implícito en las fuentes consideradas, de allí que el retrovanguardismo nos permite recuperar la perspectiva palingenésica de Lugones, ya que al 
Recuperar la posición auténticamente revolucionaria de la vanguardia en la cultura, que nunca se basó, o no se basó únicamente, en su negatividad crítica, sino más bien en general, en la heterogeneidad temporal con el presente, que resulta de su tratamiento artístico del tiempo como material figurable. (Miller, 2007, p. 265) ${ }^{19}$.

Como hemos sostenido en trabajos previos (Tobares, 2017b), Lugones articuló su propuesta en torno a la recuperación del pasado clásico anclado en la herencia cultural greco-romana, -latina- en América. El supuesto detrás de esa recuperación es que la crisis evidenciaba el fin de una época marcada por el fracaso de liberalismo y de su manifestación política contemporánea, la democracia de masas. Para el poeta cordobés se había alcanzado entonces el final de la "modernidad" en el sentido del progreso optimizante. La recuperación de la tradición política clásica, griega en particular, tenía el doble objetivo de asentar un proyecto que institucionalizara un orden permanente del gobierno y asegurara una definición del pueblo que, luego de establecer las necesarias jerarquías, se impusiese y abarcase a un tiempo a la mayoría.

La concepción palingenésica implícita en el retrovanguardismo de Lugones apela como recurso fundamental a la recurrencia performativa del tiempo, y es desde aquí que construye tanto su propio lugar como enunciador como al destinatario de su discurso: las FFAA, cuyo rol era recuperar, en líneas generales, el liderazgo social:

Así, todos vosotros, todos los que seáis honrados hombres de espada, pertenecéis al linaje de los héroes homéricos. Seguid la línea de nobleza que sus hazañas os trazan desde el fondo de la antigüedad.

En tanto que otros trabajadores más obscuros y humildes, buscan en la jornada paralela de la vida, como una quimera tal vez, la posteridad de Hornero... (Lugones, 1915, p. 62).

Lugones buscaba proyectar ese liderazgo al futuro, puesto que: "El mejor de los signos es pelear por la patria. La antigüedad aseguraba con esta frase el honor de la civilización futura” (Lugones, 1915, p. 54). El vínculo cultural que hace posible el programa del poeta reside en la génesis de la cultura argentina, que ahora es revelada por el enunciado y expuesta como continuidad de aquella cultura clásica, ambas atravesadas por dichos elementos en común:

\footnotetext{
Ahora bien, esa exhibición de barbarie ante la ciudad civilizada; esa pasión impetuosa de la mujer, que engendrando la querella de Aquiles y Agamenón, forma la peripecia fundamental del poema y desarrolla el sentimiento caballeresco hasta las alturas de la hazaña; esa predilección por el perro y por el caballo, que cierra el poema con este elogio supremo a Héctor "domador de corceles"; ese fatalismo mezclado de ruda fe en el destino y en la divinidad; ese papel importante del baqueano en las marchas: ese egoísmo del combate singular, que, ante todo, es proeza de caudillo; esas provocaciones por medio de la jactancia personal; esa voracidad carnívora, esa rapacidad cuatrera, esa indisciplina voluntaria, ese amor de las carreras, esa hospitalidad fidelísima, hasta ese respeto singular por la medicina promediada de magia, ¿no es verdad que ofrecen semejanzas curiosas con las cualidades y defectos de nuestros grandes montoneros, hasta formular imperiosamente una verdadera identidad psicológica? (Lugones, 1915, p. 56).
}

Junto a la "identidad psicológica" aparecen implícitamente enunciadas las jerarquías sociales como una característica que distingue a los caudillos de las bases. Y es en la definición de esas bases donde se apoya el retorno de la cultura y el orden.

\section{EL PUEBLO: DE LA GUERRA AL GOBIERNO}

Pueblo, como metáfora, tiene capacidad apotropaica en al menos tres aspectos: 1) establece un colectivo que define al mismo tiempo una identidad y la diferencia, y que ejecuta en dicha identidad un acto de liberación a lo largo del tiempo el establecimiento de este colectivo define a lo político; 2) funda una autoridad, la misma cristaliza en la noción de soberanía arrancada a la divinidad, y 3) hace posible regular lo extraordinario estableciendo jerarquías y dando lugar a un orden. Aquella autoridad tomada de lo divino establece una estratificación que refuerza lo político.

Pueblo como metáfora permite hacer confortable lo incómodo: 
Lo que se ha hecho identificable mediante nombres es liberado de su carácter inhóspito y extraño a través de la metáfora, revelándose, mediante la narración de historias, el significado que encierra. El pánico y la paralización (...) quedan disueltos en la apariencia de unas magnitudes de trato calculables y unas formas de trato reguladas (Blumenberg, 2003, p. 14).

Desde la clave de un humanismo universalista, Lugones define al pueblo por oposición al extranjero: éste es egoísta, determinado por el contexto del cual no forma parte y, por lo tanto, incapaz de decidir libremente. En este sentido, "Un extranjero puede ser tanto aquel que ha nacido en otro territorio como uno nacido en territorio argentino, pero no comparte la comunidad ética, cuyo sentido el pensador reenvía al ethos griego" (Ferras, 2008, p. 194).

Pero no sólo eso, en la lógica implícita de guerra del poema nuestro autor funda las bases de la sociedad a futuro, un orden caracterizado por surgir del campo de batalla mismo, y atravesado, como hemos mencionado, por las jerarquías castrenses que se constituyen en el elemento primordial de la democracia.

El primer elemento a considerar entonces no era la política en sí como medio para poner en funcionamiento a la democracia, puesto que ya en la Grecia clásica las audiencias públicas contaban con elocuentes oradores, sino que lo que realmente importaba era "la formación del respeto por el pueblo" (Lugones, 1915, p. 36).

Entendiendo la necesaria participación del pueblo en el gobierno, el medio más exitoso de su organización no dependía de ordenamientos externos -divinos o superiores-, sino que ello era obra de la propia acción racional del pueblo. Así, Atenas es recuperada como culminación del proceso iniciado con la guerra:

(...) la democracia y la división de los cargos públicos llegaron en ella al gobierno directo del pueblo por el pueblo, así como a la adjudicación dé aquellos por votación y por sorteo, sin excluir el mismo comando del ejército; pero aquella guerra primitiva fundó en Grecia la nacionalidad (Lugones, 1915, p. 38).

Y aunque "el soldado no cuenta, según dije antes, a no ser como fondo difuso del cuadro que tiene por personajes a los jefes; pero, en el mismo poema, nótase acá y allá el germen de la entidad popular que va a formarse" (Lugones, 1915, p. 35). Así, el germen del pueblo se hallaba en el campo de batalla, un campo compartido desde sus respectivos lugares por jefes y soldados, que llevaba a los primeros a tener una necesaria y creciente consideración por sus tropas:

La nobleza manda todavía con absolutismo despótico, permitiéndose golpear con sus cetros al plebeyo que protesta, y celebrando sus consejos de guerra sin darle participación alguna; pero en aquella oposición existe ya un rasgo de personalidad rebelde, y las mismas proclamas de los jefes, aunque escasas, revelan que se tenía en cuenta al pueblo más de lo que se aparentaba. Así, después del consejo de guerra del canto II, con motivo del sueño infausto de Agamenón, los pueblos se reúnen para escuchar la proclama con que éste les participa la decisión de la retirada; y sólo la palabra de Ulises, que habla a cada soldado en términos de reflexiva consideración, impide aquel paso extremo. Aquí es el pueblo quien decide, a pesar de la resolución del jefe, y no obstante haberle causado esta última indecible alegría, puesto que significaba el regreso a los hogares largo tiempo abandonados (Lugones, 1915, p. 35).

Si seguimos a Hans Blumenberg, aquel término, "que se ha hecho identificable mediante nombres, es liberado de su carácter inhóspito y extraño a través de la metáfora, revelándose, mediante la narración de historias, el significado que encierra" (Blumenberg, 2003, p. 14). En nuestro caso el término en cuestión es el pueblo, y en El ejército de la Ilíada es posible advertir el uso metafórico, aquello no visto y que llena un vacío del poema para fijar el sentido de un programa político que vinculará en el orden social futuro al pueblo con las FFAA, haciendo del primero el imprescindible espacio de acción política de la renovada aristocracia militar propuesta por el poeta.

\section{EL UMBRAL DEL RENACIMIENTO}

El Ejército de la Ilíada puede ser leído entonces como un "programa político" liminar ${ }^{20}$, una guía en la que se trazan líneas de acción a seguir, cuyo fundamento se halla en la recuperación de la trilogía estética de 
bien, verdad y belleza, que permitirá (re)fundar un orden social racionalmente justo entre pueblo y gobierno. Para seguir con nuestro argumento, hemos relevado aquellos aspectos que a nuestro entender permiten señalar cuáles eran los principios que articularían aquel orden, en función de la recuperación palingenésica de la civilización, el rol de las FFAA, la necesaria revolución y el (re)establecimiento de los principios patrióticos y nacionales.

El programa ideado por Lugones hace operativo el "tiempo nuevo", ese momento liminar que señala de forma simultánea, por un lado, el retrovanguardismo de su discurso como propuesta que recupera el pasado clásico y se proyecta al futuro, y, por otro lado, condensa el espacio de experiencia caracterizado por una democracia liberal que ha agotado su tiempo y que ha entrado -según Lugones- en una crisis terminal. A tono con el carácter retrovanguardista de El Ejército de la Ilíada, el autor proyecta, según hemos analizado, una nueva sociedad anclada en presupuestos democráticos, pero atravesada por la jerarquía de las FFAA a las que atribuye el estatus de únicas garantes del orden social.

En la base del programa estará el objetivo de la recuperación de la civilización clásica, por lo tanto, en primer lugar debía establecerse la continuidad de aquélla en Argentina. Para ello, una de las primeras indicaciones que hace Lugones a sus interlocutores es basar sus lecturas en los autores griegos, ya que sus ideas "representan el fundamento de la civilización a la cual pertenecemos, y porque constituyen la herencia del estado social más feliz que hayan conocido los hombres blancos" (Lugones, 1915, p. 15). De esta manera, fijaba un sentido a la recuperación del pensamiento heleno, el cual llevaba implícito el principio estético basado en la razón y la belleza.

Pero, ¿cuál era la base misma de aquella civilización? Para nuestro autor, ella residía en la "solidaridad primitiva" con el jefe, el cual frente a una ofensa moviliza sus recursos e influencias para "nacionalizar" el conflicto. Así, la crisis general "forma el origen de la nacionalidad y de la raza como ideas transformadas luego en hechos” (Lugones, 1915, p. 39).

Frente a la crisis, ineludiblemente la guerra adquiere una nueva connotación, que es, en sí misma, factor de civilización si se ejecuta correctamente:

(...) la guerra, al efectuar progresivamente, bajo la suprema sanción del peligro y la ratificación solemne de la sangre, la solidaridad de las familias, tribus, confederaciones, nacionalidad y raza, fue el elemento más activo de civilización política y social.

Obsérvese, ahora, esta consecuencia al parecer extraña.

La guerra proviene de la solidaridad, es decir, del mismo principio que, generalizado por la filosofía en el espíritu, así como por la facilidad de relaciones en el tiempo y en el espacio, niega ahora la guerra; de donde resulta que lo esencial es aquel principio, no sus agentes, y que cuando se asigna a la guerra un carácter civilizador, no es en abstracto ni en absoluto, sino con relación a un medio determinado, fuera del cual puede convertirse en causa de retroceso y de barbarie (Lugones, 1915, pp. 39-40).

La estructura jerárquica es condición para que la guerra no degenere un esfuerzo social que se proponga un desarrollo civilizado. Y ello queda explícitamente señalado por nuestro autor al aludir a la figura de Héctor, "quien representa el carácter superior del guerrero futuro, más simpático a nuestros sentimientos civilizados" (Lugones, 1915, p. 52). Ello, en razón de que frente a la fuerza bruta y eficiencia de Aquiles en el combate: "Sus consideraciones cuando el combate decisivo cuyo resultado funesto para él calcula, reconociéndose inferior a su adversario, son las de un héroe reflexivo en quien el sentimiento del honor supera ya a la bravura" (Lugones, 1915, p. 52).

Ese dominio del miedo sobre el que prevalece el honor bélico es lo que define, "en gran parte, el coraje de la civilización" (Lugones, 1915, p. 52). El sacrificio en pos de la civilización era entonces lo que definía el perfil del guerrero civilizador de Lugones, quien se preguntaba retóricamente si esa acción no era la "fiera aceptación de la muerte que constituye el principio del heroísmo" (Lugones, 1915, p. 61). Y es este minimum temporal ${ }^{21}$ de aceptación de la muerte lo que cerraba y abría al mismo tiempo el ciclo del renacimiento cultural. 
Las FFAA aparecen entonces como las promotoras del cambio de ciclo y la corporación que más fielmente representa al pueblo. Como hemos visto, el vínculo entre jefes y soldados era una de las herencias de la cultura clásica, vínculo que, según el poeta, se estrechaba al constituirse las tropas en entidad popular.

Aquella "república militar en campaña", entidad de carácter local renacía en

(...) nuestras montoneras, bajo un concepto de nacionalidad todavía supeditado a los intereses egoístas; exagerando por igual la influencia del caudillo que los comandaba con despótica dureza, pero a quien obedecían solamente. Algunos, como Quiroga, gozaron ante el vulgo hasta de la vinculación sobrehumana atribuida a los héroes homéricos (Lugones, 1915, p. 37).

Lo que se recobraba era "el gran destino de las espadas libres: escribir en tablas perdurables la libertad, esa lección de la justicia” (Lugones, 1915, p. 40). Así, las FFAA serán quienes encarnen el ideal estético y lo lleven a la práctica mediante la extensión del principio de solidaridad, principio que, además de generar el sentimiento patriótico, afirmaba la unidad de espíritu nacional.

En 1912 escribía Lugones que la situación imperante había "reducido la autoridad bajo todas las formas gubernativas, a esta única expresión: el ejército. De él depende ahora todo el sistema institucional” (López y Korn, 2011, p. 151).

Las FFAA son propuestas, según hemos visto, como las restauradoras de las instituciones políticas y sociales corrompidas por la demagogia democrática, la cual no hizo más que coartar el atributo distintivo del ciudadano, su libertad y la equivalencia de "los capaces". Su arremetida contra la democracia es la crítica de la artificial representatividad de los sistemas democráticos para legitimarse. Éstos son criticados desde dos frentes: por un lado, el sometimiento del individuo y, como consecuencia, la coerción "que inhibe el progreso de la sociedad" (López y Korn, 2011, p. 25), y, desde el otro lado, la democracia es la expresión de las multitudes que "nivelan hacia abajo las potencias humanas" (López y Korn, 2011, p. 25).

Sin embargo, debía recuperar y definir el carácter militar; de allí que las FFAA no debían ser ejecutoras de la violencia per se, sino que debían formarse siguiendo el modelo griego de las palestras, que "fueron las únicas escuelas de la Grecia primitiva, poseían a fondo la gimnasia militar y el orgullo de la destreza bella, pues dicha enseñanza representaba la negación de la fuerza inculta" (Lugones, 1915, p. 33).

Y si había que encauzar la fuerza bruta dentro de los límites del ideal estético, aquélla debía conservar cierto "aspecto terrorífico del hombre armado, por otra parte eficaz en la lucha cuerpo a cuerpo" (Lugones, 1915 , p. 45), en particular - por razones de prestigio y jerarquía, "los jefes ostentaban una heroica barbarie de costumbres y de maneras" (Lugones, 1915, p. 47).

La fuerza bruta encontraba su contrapeso en el concepto de heroísmo. Ya hemos mencionado que Héctor, quien aun en desventaja reflexiona sobre su inevitable destino, es considerado el arquetipo del soldado. Lugones entiende que la constancia es la base de ese heroísmo, que en el campo de batalla encuentra su razón última en: "La venganza griega que no admitía como atenuantes del homicidio la casualidad, ni aun la infancia del agresor, es el móvil de todas aquellas bravuras” (Lugones, 1915, p. 50).

La guerra, como hemos mencionado, no sólo es el medio para impulsar el desarrollo de la civilización, sino que además es recuperada como el soporte de la solidaridad, que unifica las causas individuales de los jefes y las convierte en causa nacional. En tanto medio, la guerra y las FFAA no debían desvirtuarse en:

Esa exageración anacrónica cuyo sostén demanda absorciones injustas y excesivas del bien común, en razón directa de su progresiva anomalía, es lo que llamamos militarismo y combatimos a nombre de la civilización futura, oponiendo a la pesadumbre de su materia, la palabra que es el viento del espíritu (Lugones, 1915, p. 40).

Entonces, para el poeta, la guerra no era más que el instrumento de cambio social, era la praxis revolucionaria.

$\mathrm{Si}$ asumimos que:

La revolución es distinguida como una forma trascendente de resistencia política, porque en su esencia está contenido el fin subversivo y transgresor del orden iuspolítico del Estado. No se resiste en revolución para conservar, sino para trascender (Pérez Llody, 2017, p. 445). 
En Lugones la revolución es cambio palingenésico, y, como hemos visto, la transcendencia residía, en última instancia, en la belleza entendida como equidad -proporcionalidad armónica-, cuya manifestación permanente es la poesía como forma superior de la lengua.

Pero la revolución llevaba implícito el orden social contenido en el proyecto, que separaba a la aristocracia del pueblo, y dentro de la aristocracia, quien tenía la voz autorizada era el propio poeta: "El trovador cuenta, exclusivamente, con un público de señores, y no celebra sino hazañas aristocráticas. La masa popular constituye, apenas, el fondo difuso en el cual destácanse aquéllos" (Lugones, 1915, p. 19)22. Esto era consecuencia, como hemos visto, de las jerarquías impuestas por la guerra, pero dichas jerarquías no eran una situación de natural obediencia, lo cual hubiera sido una contradicción en los fundamentos del proyecto, sino que la distinción se basaba en que la aristocracia era la receptora y ejecutora de un reclamo general y libre, por lo tanto, justo y legítimo. Así: "Aquiles, en su mencionada proclama a los mirmidones, recuerda los reproches y amenazas con que ellos protestaban de la inacción del caudillo: libertad extrema, por cierto, tratándose del más bravo y rencoroso de los jefes helenos" (Lugones, 1915, p. 35). De esta manera, la fortaleza de los jefes era directamente proporcional a la fuerza del reclamo de aquellos sobre los que se ejercía la autoridad. Para Lugones el soldado/ciudadano y su autoridad dependían de la capacidad que tuviesen los jefes para encauzarla en pos de un objetivo común.

El poema de Homero es recuperado como

(...) la inauguración de la patria en la solidaridad persistente de las tribus, que afirman su seguridad y su integridad con el deber de venganza: una idea rudimentaria, pero efectiva, de justicia.

Por eso, también, los pueblos evolucionaron hacia la democracia; pero allá, sobre el campo de batalla, los jefes supieron mantener su condición superior por derecho divino, con esa excelencia de valor y ese privilegio del peligro que constituyen la respetabilidad de las aristocracias (Lugones, 1915, pp. 40-41).

El orden social es entonces resultado del prestigio de los jefes aristocráticos, portadores de actitudes que los distinguen del resto de quienes necesariamente deben formar parte de la revolución, pero dicho prestigio, para ser legítimo, debe ser la consecuencia del apoyo popular y no sólo ser la aplicación de la fuerza bruta, del militarismo.

Como hemos visto, la triada estética sostenida por Lugones articulaba su proyecto palingenésico y, si el bien y la verdad aparecen atravesados por el tiempo en un contexto, la belleza es el único ideal trascendental y permanente. Es por esto que la belleza constituía la base inmutable del orden social, que para nuestro autor debía ser atributo exclusivo de la aristocracia militar, por ello es que "en una civilización tan guerrera como aquélla, el deber de belleza concernía ante todo al militar" (Lugones, 1915, p. 17).

Y este deber se cumplía frente al pueblo que, como hemos mencionado antes, sólo aparecía como trasfondo de las acciones de los jefes heroicos. Así, en tanto espectador, el pueblo aparece como el interlocutor exclusivo de las FFAA: "El combatiente de la Ilíada es, pues, antecesor directo de aquellos soldados de Jenofonte, tan revoltosos e igualados a sus jefes, como accesibles a la palabra racional, siempre poderosa en Grecia" (Lugones, 1915, pp. 35-36). Ello implicaba entonces que las jerarquías eran justas, democráticas y necesariamente desiguales, pero no asimétricas.

Como hemos señalado al analizar la tetralogía del Centenario, en particular en Odas, la patria constituye el sustrato del espíritu nacional y el marco del (re)nacimiento cultural. Es en este marco donde el arquetipo del héroe militar, Héctor, adquiere un lugar superlativo como el modelo a seguir puesto que "la psicología del jefe troyano denuncia un estado de civilización sensiblemente superior a la griega, al poseer el concepto unificador de la patria" (Lugones, 1915, p. 30). El poema en general, según la interpretación retrovanguardista de nuestro autor, contiene "la idea de patria" repetida con tal frecuencia que, sin suponer una identidad nacional griega, hace imposible considerar en el poema homérico: "Este fundamento del patriotismo en el culto de los antepasados (...) es una idea netamente griega" (Lugones, 1915, pp. 38-39).

Y el contexto en el que los jefes heroicos exhiben sus virtudes es, como vimos antes, la guerra, que aparece como acción civilizadora y el hecho fundador de la nacionalidad: 
Si algún héroe resulta superior, es, al fin de cuentas, Héctor el troyano. No puede, siquiera advertirse en esos cantos el ideal expansivo del espíritu griego que recibió después el nombre de helenismo. Lo único que indican como estado político y social es una nacionalidad en formación, por los intereses coincidentes de una multitud de caudillos, lo bastante civilizados para comprender la ventaja inmediata de la unión (Lugones, 1915, p. 20).

Así, aquella solidaridad aristocrática extendida que fundaba la nación se hallaba en el génesis de la Argentina al igual que lo había estado en Grecia, ya que los jefes heroicos:

(...) iguales entre sí, reconocían como jefe accidental al más poderoso: Agamenón, rey de Micenas: pero reservándose el derecho de combatir o retirarse a voluntad, como Aquiles. Del propio modo obraron nuestros caudillos, hasta los días bien próximos de la guerra con el Paraguay (Lugones, 1915, p. 37).

En última instancia, como vimos, la única desigualdad era aquella que se establecía entre la aristocracia de los jefes y el pueblo de soldados, sin que ello impidiera la capacidad de éstos de expresar libremente sus reclamos a los jefes. Sin embargo, en el interior de la aristocracia la desigualdad no existía:

(...) la cortesía caballeresca fundada en los deberes de la hospitalidad, tan sagrados para los griegos, engendra en el canto VI el bello encuentro del troyano Glauco con Diomedes, quien, al reconocerle en el combate como una antigua relación de su familia, le propone la suspensión de toda hostilidad entre ellos, y el cambio de armas en prueba de amistad. Los héroes se abrazan en el campo de batalla, y el trueque se efectúa, aunque las armas de Diomedes eran de oro y las de Glauco de bronce (Lugones, 1915, p. 51).

De esta manera, el núcleo del nuevo orden dependía de la cohesión interna de las FFAA como la organización que daría a la sociedad la estabilidad necesaria en el futuro. Estabilidad nacida de la "suspensión de toda hostilidad" de los jefes, de la solidaridad de cuerpo que unificaba a la aristocracia militar, y que, en consecuencia, consolidaría al pueblo, al borrar las diferencias sociales para dar así unión a la nación.

\section{Consideraciones Finales}

La recuperación mitificada del pasado establece los elementos constitutivos de la matriz discursiva, aquello que debía (re)crearse por primera vez, de allí el carácter performativo del discurso de Lugones. Esta recuperación del pasado fundaba una nueva temporalidad, nacida de un proceso revolucionario que proyectaba el proceso a futuro. Éste es el carácter retrovanguardista contenido en el proyecto político de Lugones. El objetivo era abrir un nuevo camino a la trascendencia más allá de la Modernidad. Esta nueva temporalidad se encarnaba en el renacimiento de la nueva communitas, que superaba la fragmentación social, la cual en el caso argentino se había producido por el proceso inmigratorio y que el orden liberal no había podido resolver.

En este sentido, el proyecto de Lugones puede ser considerado como la manifestación de un espíritu de época, que en las dos primeras décadas del siglo XX cuestionaba a la Modernidad asentada en el liberalismo y a la idea de "progreso" que contenía. El quiebre moral e ideológico que supuso la Gran Guerra impulsó a los sectores críticos del liberalismo a recuperar el paraíso perdido de una existencia caracterizada por el exilio social. Como lo hemos analizado, el retrovanguardismo nos permite advertir la doble operación de Lugones: un proyecto que se estructuraba sobre el renacimiento palingenésico de la nación, proyecto cimentado en modelos arquetípicos de un estado intacto de la comunidad in illo tempore, en el que imperaba una realidad organizada del ser.

Llegada la "hora de la espada", debería haber no sólo un brazo fuerte que la empuñara con firmeza, sino un cuerpo social que estuviera dispuesto a sostenerla. Eso es lo que Lugones se propone con El Ejército de la Iliada: explicitar cuales eran los valores trascendentales que harían de las FFAA un grupo homogéneo que frente a la sociedad argentina fuera capaz de guiarla en el inicio del nuevo tiempo. Un tiempo que tenía su origen en ese año cero que abría el umbral a un nuevo tiempo, en el que el caos daría lugar a un orden anclado en la redefinición de lo bueno, lo verdadero, pero principalmente por lo bello y justo. 
Pero, ¿cuáles eran las posibilidades concretas de que el destinatario actuara como interlocutor del poeta? Por lo dicho hasta aquí, se podría considerar que Lugones puso en escena un "acto de magia mitopoética" en el que intentó sentar las bases de un proyecto de regeneración social, que articulaba al Estado con el pueblo a partir de la identificación del primero como instrumento de una aristocracia militar de la que el propio poeta formaba parte, y de una sociedad organizada en función de las FFAA. Este acto fue El Ejército de la Ilíada que, articulado con la tetralogía del Centenario, brindaba una sensación de trascendencia a quienes, como Lugones, buscaban fuentes de trascendencia entre los escombros del cataclismo producido por la Modernidad.Esto daba lugar al esfuerzo creador de una búsqueda por establecer un orden social e incluso por trazar el sentido de inmanencia ad aternum.

Así, según lo hemos mencionado, la tetralogía de Lugones recupera el pasado y proyecta al futuro el Centenario como mínimum temporal. Su "homenaje a la patria" exponía el recorrido retrovanguardista al fusionar, en 1910, el pasado con el futuro, en un recorrido que había comenzado en 1908 y que marcaba un hito hacia 1915.

Su programa se articulaba en torno al eje del uso proporcionado estéticamente de la fuerza coercitiva del Estado. La única manera de hacer esto era usando racionalmente la fuerza bruta bajo la potestad civil, que será postulada como la base del orden social en el orden futuro. En relación con dicha potestad nuestro autor se atribuía un lugar referencial, dado que era el encargado de establecer el tipo de prevalencia que existía entre el ámbito civil y el militar.

No obstante, dicha prevalencia y, por extensión, la representación del pueblo por sí mismo- implicaba para Lugones el gobierno directo, y ello sólo sería posible si el sufragio expresaba el entendimiento de los ciudadanos sobre los asuntos públicos.

Es sobre una base popular definida en esos términos, y atravesada por las jerarquías sociales, que se apoya el retorno de la cultura y el orden. Un orden en el que el pueblo deviene en metáfora de lo no visto para llenar un vacío que fija el sentido de un programa político que vinculará en el orden social futuro al pueblo con las FFAA haciendo del primero el imprescindible espacio de acción política de la nueva aristocracia militar.

La activación de ese minimum era la revolución, entendida como cambio palingenésico cuya transcendencia residía, en última instancia, en la belleza entendida como equidad -proporcionalidad armónica-, y cuya manifestación permanente era la poesía como forma superior de la lengua. Pero la revolución llevaba implícito ese orden social contenido en el proyecto, que distinguía a la aristocracia del pueblo, y, en interior de la primera, quien tenía la voz autorizada era el propio poeta. El núcleo del nuevo orden dependía de la necesaria cohesión interna de las FFAA, que, como corporación, darían a la sociedad la estabilidad necesaria en el futuro. Esa estabilidad nace de la "suspensión de toda hostilidad" de los jefes, de la solidaridad de cuerpo que unificaba a la aristocracia militar y que consolidaría, en consecuencia, al pueblo borrando al mismo tiempo las diferencias sociales y dando unidad a la nación. Se trata de una unidad perdida en el propio espacio de experiencia de Lugones como consecuencia de los cambios sociales y políticos que tenían lugar en la Argentina de 1910, en la que el poeta procuraría hacer renacer aquello que se había olvidado.

\section{FuenTES ${ }^{23}$}

Lugones, L. (1910a). Las Limaduras de Hephastos. Piedras Liminares. Buenos Aires: Moen y Hermanos Impresores. Lugones, L. (1910b). Odas Seculares. Buenos Aires: Moen y Hermano Editores.

Lugones, L. (1910c). Las Limaduras de Hephastos. Prometeo (Un proscripto del sol). Buenos Aires: Otero Impresores. Lugones, L. (1910d). Didáctica. Buenos Aires: Otero y Cía. Impresores.

Lugones, L. (1915). El Ejército de la Ilíada. Buenos Aires: Otero y Cía. Impresores. 


\section{Referencias bibliográficAs}

Angenot, M. (2013). La democracia es el mal. Un siglo de argumentación antidemocrática en la extrema izquierda, 1815-1914. Estudios. Revista del CEA, 29 141-154 Recuperado de: https://revistas.unc.edu.ar/index.php/restu dios/article/view/5344/5506

Anderson, B. (1993). Comunidades Imaginadas. Reflexiones sobre el origen y la difusión del nacionalismo. México: Fondo de Cultura Económica.

Bauman, Z. (2017). Retrotopia. Epublibre. Recuperado de: http://bajafiles.com/f/Wfwipk, acceso 22 de abril de 2018.

Benoist, A. (2010). Más allá de la derecha y de la izquierda. El pensamiento político que rompe esquemas. Barcelona: áltera.

Blumenberg, H. (2003). Trabajo sobre el mito. Barcelona: Paidós.

Bracamonte, J. (2009). Contra la mediocridad: individuo, multitud y estado en cuatro ensayistas argentinos. Córdoba: Universidad Nacional de Córdoba.

Bustelo, N. (2012). Entre la épica nacional y las críticas antiparlamentarias. Tensiones en el "modernismo nacionalista" de Leopoldo Lugones. Revista Electrônica da ANPHLAC, 12. 85-111 Recuperado de: http://revistas.fflch.usp. br/anphlac/article/view/1332/1203, acceso: 20 de noviembre de 2017.

Conil Paz, A. (1985). Leopoldo Lugones. Buenos Aires: Librería Huemul.

Cruz Rodríguez, E. (2011). De la historia conceptual de lo político a la historia de los discursos políticos. Una aproximación. Revista Historia 2.0, 1. 57-71 Recuperado de: https://www.researchgate.net/publication/277731071_De_la_historia_conceptual_de_lo_politico_a_la_ historia_de_los_discursos_politicos_Una_aproximacion, acceso: 16 de abril de 2019

Devoto, F. (2008). Acerca de un intelectual extremo y sus fracasos. El caso de Leopoldo Lugones político. Estudios Sociales. Revista universitaria semestral, 34, 11-29. Recuperado de: http://bibliotecavirtual.unl.edu.ar/ojs/index .php/EstudiosSociales/article/download/2610/3724/, acceso: 10 de septiembre de 2018

Echeverría, O. (2009). Las voces del miedo. Los intelectuales autoritarios argentinos en las primeras décadas del siglo XX. Rosario: Prohistoria Ediciones.

Ferrás, G. (2008). Hostis y hospitalidad. Filosofía, mito y nación en el pensamiento de Leopoldo Lugones, en el periodo del Centenario en la Argentina. Co-herencia, 8. 183-208. Recuperado de: http://www.scielo.org.co/pdf/cohe/v 5n8/v5n8a07.pdf, acceso: 20 de noviembre de 2017.

Griffin, R. (2010). Modernismo y Fascismo. La sensación del comienzo bajo Mussolini y Hitler. Madrid: Akal.

Koselleck, R. (1993). Futuro pasado. Por una semántica de los tiempos históricos. Barcelona: Paidós.

Koselleck, R. (2001). Los estratos del tiempo: estudios sobre la historia. Barcelona: Paidós.

Koselleck, R. (2012). Historias de conceptos. Estudios sobre la semántica y pragmática del lenguajepolítico y social. Madrid: Editorial Trotta.

Laclau, E. (1993). Discurso. En http://biblioteca.itam.mx/estudios/60-89/68/ErnestoLaclauDiscurso.pdf Acceso: 20 de noviembre de 2017.

Laclau, E., y Chantal Mouffe (1987). Hegemonía y estrategia socialista. Hacia una radicalización de la democracia. Madrid: Siglo XXI.

López, M. (2004). Lugones: entre la aventura y la cruzada. Buenos Aires: Colihue.

López, M. P., y Korn, G. (2011). Leopoldo Lugones. Escritos Politicos. Buenos Aires: Losada.

Miller, T. (2007). Retro-Avant-Garde: Aesthetic revival end the con/figurations of twenty-century time. Filozofki Vestnik. 2, 253-265. Recuperado de: https://ojs.zrc-sazu.si/filozofski-vestnik/article/view/3186, acceso: 12 de septiembre de 2016.

Nietzsche, F. (2003). Así habló Zaratustra. Un libro para todos y para nadie. Madrid: Alianza Editorial.

Nolte, E. (2001). La influencia de Marx y Nietzsche en el socialismo del joven Mussolini. Cuaderno Gris. Época III, 5 113-160. (Monográfico: Nietzsche y la "gran política": antídotos y venenos del pensamiento nietzscheano / 
Alfonso Moraleja (coord.)). Recuperado de: https://repositorio.uam.es/xmlui/bitstream/handle/10486/172/2 2011_La\%20influencia\%20de\%20Marx\%20y\%20Nietzsche.pdf?sequence=1, acceso: 15 de agosto de 2017.

Ossorio y Florit, M., y Cabanellas de las Cuevas, G. (2010). Diccionario de Ciencias Jurídicas Políticas y Sociales. Buenos Aires: Heliasta, recuperado de: https://conf.unog.ch/tradfraweb/Traduction/Traduction_docs\%20generaux/Diccionario\%20de\%20Cie ncias\%20Juridicas\%20Politicas\%20y\%20Sociales\%20-\%20Manuel\%20Ossorio.pdf, acceso: 16 de abril de 2019.

Pérez Llody, L. A. (2017). Modernidad, progreso y violencia: algunas claves para un concepto jurídico de revolución. Problema: Anuario de Filosofia y Teoria del Derecho,11.417-464. Recuperado de: http://www.redalyc.org/artic ulo.oa?id=421950524013, acceso: 16 de abri de 2019

Popper, K. (1973). La miseria del historicismo. Madrid: Alianza Editorial.

Rosanvallon, P. (2003). Por una historia conceptual de lo político. Lección inaugural en el College de France. Buenos Aires: Fondo de Cultura Económica.

Rosanvallon, P. (2009). La legitimidad democrática: imparcialidad, reflexividad, proximidad. Buenos Aires: Manantial.

Sallenave de Saguí, T. (1984). Las ideas estéticas en Leopoldo Lugones. Instituto de Literatura Latinoamericana, 12, 97-115. Recuperado de: http://bdigital.uncu.edu.ar/objetos_digitales/4555/99-cuyo-1979-tomo-12.pdf, acceso: 12 de noviembre de 2017.

Sánchez-Prieto, J. M. (2012). Reinhart Koselleck: la interdisciplinariedad de la historia. Memoria y Civilización. Anuario de Historia, 15. 475-499. Recuperado de: https://www.unav.edu/publicaciones/revistas/index.php/m yc/article/view/1711/1580

Taylor, D.(2009). Performance e historia. Apuntes, 131, 105-123, disponible en: http://www.usc.es/export9/sites/webinstitucional/en/titulacions/masters_oficiais/mxpaamma/descargas/ PERFORMANCE-HISTORIA.pdf, acceso: 25 de mayo de 2019.

Tobares, J. (2017a). Deus ex sufragii. La construcción del pueblo en el discurso oligárquico. Córdoba, Argentina. 1890-1912. Saarbrücken: Editorial Académica Española.

Tobares, J. (2017b). La democracia como punto de fuga. El pueblo en la matriz discursiva de Alberdi y Lugones. 1863-1917. PolHis. Revista bibliográfica del programa Buenos Aires de Historia Politica, 1950-85

Torres Roggero, J. (2000). El combatiente de la aurora. Lugones, Córdoba y los inicios de la modernidad literaria. Córdoba: Alción Editora.

\section{HERRAMientas INFORMÁticas}

Atlas.Ti: WIN 7.5.9. Licencia Educativa Individual. @ 1993-2017 por Atlas.tiGmbH, Berlín.

\section{Notas}

1 http://www.laibach.org/statements/

2 El retrovanguardismo "crea el realce paradójico de la dinámica temporal de la anticipación que invierte de forma retórica. Pone este elemento temporal en primer plano y expone su naturaleza como un acontecimiento presente de esta imagen primaria y directa de la relación temporal: la retrospectiva tardía en referencia al pasado para la proyección al futuro de la vanguardia.

La aparente pérdida de 'movimiento' hacia adelante, la aparente inmovilización en la que el pasado y el presente parecen juntarse en obras retrovanguardistas, o el extraño vacío temporal en el que parece haberse suspendido la retórica utópica revivida del pasado, no es de hecho una pérdida del tiempo, sino una confrontación más directa con el movimiento aberrante del futurismo retrógrado que lleva a preguntarnos por qué la anticipación, y por lo tanto la negatividad como correlato estético, alguna vez parecían el recurso temporal exclusivo que la vanguardia tenía que transformar la cultura y explorar alternativas utópicas al orden social, sensorial y semiótico existente” (Traducción nuestra, JT).

Del original: "Retro-avant-garde in its paradoxical highlighting of the temporal dynamics of anticipation that it rhetorically inverts, brings this temporal element to the fore and derives its own nature as present tense occurrence from 
its more primary, direct figuration of temporal relation: its belated, retrospective, backwards-turned reference to the futural thrust of the avantgarde.

The seeming loss of forward "movement", the apparent stasis in which past and present seem to pool together in retroavant-garde works, or the odd temporal void in which the revived utopian rhetoric of the past appears to be suspended, is in fact not a loss of time, but a more direct confrontation with it the aberrant movement of backward referring futurism leads us to ask why anticipation, and hence negativity as its aesthetic correlate, once seemed like the exclusive temporal resource the avant-garde had to transform culture and explore utopian alternatives to the existing social, sensory, and semiotic order" (Miller, 2007, pp. 264-265).

Sobre la categoría "retro-avant-garde" y sus implicancias disciplinares y sociopolíticas. Disponible en: http://www.laib ach.org/monumental-retro-avant-garde/, acceso: 12 de septiembre de 2016.

Consideramos entonces que el retrovanguardismo es la compresión coyuntural del espacio de experiencia y del horizonte de expectativas, cuya forma histórica es el momentum revolucionario. (ver infra nota 20) Dicha compresión supone una percepción cíclica -en espiral- del tiempo, anclada en una concepción palingenésica. En este sentido, recuperamos la categoría de retrotopia que supone una negación de segundo grado de la utopía. Si esta última sostenía la idea de progreso futuro, su rechazo - negación de primer grado-, su resurrección -negación de segundo grado- implica una recuperación del pasado como un mundo ideal ubicado "en un pasado perdido/robado/abandonado que, aun así, se ha resistido a morir” (Bauman, 2017, p. [9]). Pasado que, en oposición al futuro, es capaz de proveer un mínimo aceptable de estabilidad y confianza.

3 Sobre el pensamiento de Lugones es interesante notar como su evolución intelectual se vincula al proceso estudiado por M. Angenot sobre el pensamiento de izquierda como fundamental y explícitamente antidemocrático, con argumentos que van desde la revolución stricto sensu al antiparlamentarismo y una concepción aristocrática de la política. Esta línea de pensamiento, hacia 1920, deriva al totalitarismo en su vertiente fascista con un contenido ideológico asimilable por el nacionalismo local, tal como el autor lo ejemplifica con el caso de G. Sorel. (Angenot, 2013).

Sobre la una posible malentendida "linealidad de la trayectoria" -que no es tal, sino que debe ser vista como continuidaden el socialismo de Lugones: es posible una lectura no materialista del socialismo desde Reflexiones sobre la violencia, de G. Sorel, que rompe con la linealidad marxista del socialismo y se acopla sin conflictos con el fascismo en el período considerado.

4 Para una introducción a la discusión en torno al concepto de pueblo nos remitimos a: Badiou, Alain [et al.] (2014): ¿Que es un pueblo?, Eterna Cadencia Editora. Buenos Aires. La cuestión de fondo (y sin duda historiográficamente más interesante) parece ser sin embargo “¿Por quién?” es imaginada la comunidad. Cfr. Chatterjee, Partha (2002): Comunidad Imaginada: ¿Por quién?. En Historia Caribe [en línea], II(7), recuperado de: http://www.redalyc.org/arti culo.oa? $\mathrm{id}=93720704$ acceso: 13 de noviembre de 2017

5 Definiremos al discurso político como la totalidad estructurada y significativa resultante de aquellas prácticas que establecen "una relación tal entre elementos, que la identidad de estos resulta modificada como resultado" de esas prácticas (Laclau, 1987, p. 176), que al mismo tiempo trasciende la distinción entre lo lingüístico y lo extralingüístico (Laclau, 1993, p. 15). Como conjunto de prácticas, elementos lingüísticos y no lingüísticos "constituyen un sistema diferencial y estructurado de posiciones, es decir, un discurso”. (Laclau, 1987, p. 184)

6 Si caracterizamos a la izquierda como la promotora del universalismo igualitario, economicismo, creencia en el progreso, moralismo social, y a la derecha como autoritarismo, conspiracionismo, orden moral, mentalidad obsidional y restauracionista, pereza intelectual, concepción esencialista-fetichista de la identidad, fobias diversas, como tantas otras formas de resentimiento o de sobreinversión narcisista. Desde nuestra perspectiva "La división derecha-izquierda ha nacido con la modernidad y desaparece con ella. Desde hace dos siglos, siempre ha habido una derecha y una izquierda, pero sus contenidos han cambiado continuamente. No hay derecha metafísica ni izquierda absoluta, sino solo posiciones relativas y sistemas de posiciones variables que se componen y recomponen constantemente; no se puede, si se quiere comprenderlas, abstraerlas de su contexto" (Benoist, 2010, p.51). En el presente trabajo usamos la nomenclatura para acordar términos de referencia, no para atribuirles significado.

7 Nos referimos explícitamente al trabajo de M. López, para quien "El veneno en el Tigre es la solitaria decisión de quien fracasa en su proyecto fundamental" (2004, p. 15) y al de O. Echeverría, quien concluye que el suicidio de Lugones "puede pensarse como el final de una historia de sueños grandilocuentes que nunca le permitieron disfrutar de logros significativos. Fue, por lo mismo, el desenlace de una historia de inseguridades y frustración” (2009, pp. 182-183). En ambos casos se equipara apresuradamente una decisión personal con el éxito o fracaso del proyecto político.

8 Siguiendo a E. Colon, quien analiza el impacto de la publicidad en la construcción de identidad contemporánea, en tanto es una de las múltiples narrativas que ocupa la noción de verdad. Esta "se disuelve entre múltiples opciones que simultáneamente menoscaban la posibilidad de lo verdadero, así reforzando el control social” (Colón, 2010, p. 193). En este sentido, lo ontológico, "el yo deja de definirse como una esencia en sí, y pasa a verse como el producto de múltiples contextos, construcciones y reconstrucciones” (Colón, 2010, p. 193), es decir, puede ser parte de la enunciación discursiva. 
9 "El término «palingenesia» y su adjetivo correspondiente, «palingenésico», llevan implícito el significado de «renacimiento», «nuevo nacimiento»y «regeneración»", en el contexto de la década de 1920 y 1930 , "hace referencia a la fantasía utópica de los revolucionarios políticos y sociales que creen estar inaugurando una era radicalmente nueva." (Griffin, 2010, p. 23)

10 Cfr. Medrano Pizarro, Juan (1998): Lugones y la guerra. Épica y violencia. Nueva Revista de Filología Hispánica,2, 357-393, recuperado de: http://nrfh.colmex.mx/index.php/nrfh/article/view/2059/2050, acceso: 12 de noviembre de 2017.

$11 \mathrm{La}$ (contra)revolución no deja de ser revolucionaria porque reacciona contra el socialismo, el conservadurismo y la modernidad liberal e instituye una nueva temporalidad (Griffin, 2010, p. 255).

La definición no es esencialista sino discursiva y genérica, un tipo ideal para analizar el corpus documental. En este sentido, la utilizaremos como "punto de vista selectivo preconcebido" (Popper, 1973, p. 165) para abordar el caso estudiado en relación al concepto pueblo como construcción. De esta manera, la categoría revolución nos permite dar cuenta de que la modernidad que estructura el proyecto de Lugones implica "una vuelta a, esto es, una rebelión contra la presión del medio, exaltador de la fuerza y de la practicidad exterior; un regreso a la trascendencia” (Torres Roggero, 2000, p. 20).

12 Planteamos el análisis de la obra de Lugones desde una perspectiva metodológica, en la que se aborda al corpus documental como discurso (ver supra, nota 5); la consideramos al mismo tiempo repertorio performativo y archivo histórico, ello nos permite recuperar y poner en relieve "las prácticas encarnadas que destilan significado de los acontecimientos pasados, los almacenan y encuentran modalidades encarnadas para expresarlos en el aquí y en el ahora, manteniendo siempre un ojo en el futuro" (Taylor, 2009, p. 109).

13 En este sentido es imposible no tener presente la idea planteada por Nietzsche sobre "la muerte libre" aquella debía acontecer "a tiempo", ser victoriosa, siendo además importante "morir en la lucha y prodigar un alma grande" (Nietzsche, 2003, p. 119). Todo ello daba lugar al nacimiento del "hombre superior". Luego de proclamar "la muerte de Dios" dirá Nietzsche por boca del eremita: "Sólo desde que él yace en una tumba habéis vuelto vosotros a resucitar. Sólo ahora llega el gran mediodía, sólo ahora se convierte el hombre superior -ien señor!” (Nietzsche, 2003, p. 390)

$14 \mathrm{La}$ inclusión negativa funciona políticamente en el discurso como fundamento del antagonismo político, definiendo no sólo una "frontera" frente al otro externo a la comunidad imaginada, sino asignando jerarquías (con la consecuente desigualdad) y funciones a los miembros de la propia comunidad. En este sentido, la organización social así entendida es potencialmente oligárquica como lo hemos estudiado en trabajos previos (Tobares, 2017a, p. 185).

15 El cambio de perspectiva de Lugones, la toma de conciencia como enunciador de un discurso en el que era posible clausurar el tiempo cronológico y asentar un proyecto político en un tiempo mitológico e implementarlo en clave revolucionaria es uno de los elementos que estructuran Prometeo. Cfr. Torres Roggero, Jorge (1977): La cara oculta de Lugones. Buenos Aires. Ediciones Castañeda.

16 Fragmento de "Las Limaduras de Hephaestos". II, Prometeo. En J. Bracamonte (2009), Contra la mediocridad: individuo, multitud y estado en cuatro ensayistas argentinos (p. 239). Córdoba: Universidad Nacional de Córdoba.

17 Asumimos que los conceptos poseen una estructura temporal y "un concepto tendrá distintas valoraciones temporales. Hay conceptos orientados al pasado, que conservan grabadas experiencias antiguas y que se cierran frente a cambios en su significado, y otros conceptos que anticipan el futuro" (Koselleck, 2012, p. 46). Y democracia en el contexto de 1910 en Argentina sintetiza esas múltiples temporalidades y significados.

18 Entendemos que "la experiencia y la expectativa son dos categorías adecuadas para tematizar el tiempo histórico por entrecruzar el pasado y el futuro. Las categorías son adecuadas para intentar descubrir el tiempo histórico también en el campo de la investigación empírica, pues enriquecidas en su contenido, dirigen las unidades concretas de acción en la ejecución del movimiento social o político" (Koselleck, 1993, p. 337).

19 Del original: "recover the avant-garde's authentically revolutionary position in culture, which was never, or never solely, based on its critical negativity, but rather more generally on temporal heterogeneity to the present, which results from its artistic treatment of time as a figurable material"

20 Definido al abordar los ritos de paso como "el estado del sujeto ritual es ambiguo; ya no se encuentra en el estado antiguo pero tampoco ha alcanzado el nuevo todavía” (Griffin, 2010, p. 150).

21 Koselleck lo define como aquello que introduce lo novedoso en el ciclo temporal, como "El continuo que une la experiencia anterior y la expectativa de lo que vendrá se rompe y debe constituirse nuevamente. Es este mínimo temporal del antes y el después irreversibles el que introduce las sorpresas en nosotros" (Koselleck, 2001, p. 39).

22 Así como el eremita de Nietzsche había aprendido que había cometido "la tontería propia de los eremitas, la gran tontería: me instalé en el mercado". De manera que "cuando hablaba a todos no hablaba a nadie" (Nietzsche, 2003, p. 389).

23 Agradecemos a la Biblioteca Nacional de Maestros por facilitarnos las fuentes aquí analizadas. 